\title{
Preclinical and Early Clinical Investigations Related to Monoaminergic Pain Modulation
}

\author{
Kirsty Bannister, Lucy A. Bee, and Anthony H. Dickenson \\ Department of Neuroscience, Physiology and Pharmacology, Division of Bioscience, University College London, London \\ WC1E 6BT, United Kingdom
}

\begin{abstract}
Summary: The balance between descending controls, both excitatory and inhibitory, can be altered in various pain states. There is good evidence for a prominent $\alpha_{2}$-adrenoceptor-mediated inhibitory system and $5-\mathrm{HT}_{3}$ (and likely also 5- $\mathrm{HT}_{2}$ ) serotonin receptor-mediated excitatory controls originating from brainstem and midbrain areas. The ability of cortical controls to influence spinal function allows for top-down processing through these monoamines. The links between pain and the comorbidities of sleep problems, anxiety, and depression may be due to the dual roles of noradrenaline and of 5-HT in these functions and also in pain. These controls appear, in the cases of peripheral neuropathy, spinal injury, and cancer-induced bone pain to be driven by altered peripheral and spinal neuronal processes; in opioid-induced hyperalgesia, however,
\end{abstract}

the same changes occur without any pathophysiological peripheral process. Thus, in generalized pain states in which fatigue, mood changes, and diffuse pain occur, such as fibromyalgia and irritable bowel syndrome, one could suggest an abnormal engagement of descending facilitations with or without reduced inhibitions but with central origins. This would be an endogenous central malfunction of top-down processing, with the altered monoamine systems underlying the observed symptoms. A number of analgesic drugs can either interact with or have their actions modulated by these descending systems, reinforcing their importance in the establishment of pain but also in its control. Key Words: 5-HT receptors, 5-HT, serotonin, noradrenaline, RVM, rostral ventromedial medulla, opioidinduced hyperalgesia, neuropathy, fibromyalgia.

\section{PAIN, COMORBIDITIES, AND MONOAMINES}

Pain and mood share certain neurological pathways in the CNS and have overlapping neurochemical bases, in particular their modulation by monoamine systems. This provides the substrate through which pain can influence mood, giving rise to comorbidities or secondary symptoms such as anxiety and depression, ${ }^{1,2}$ and by the same continuum allows mood to exacerbate pain; indeed, patients with depression often present with symptoms that include medically unexplained pain, with the mean prevalence of such occurrence cited as 65\%. ${ }^{1,3}$ Emotional facets of nociception play a significant role in the pain experience, with fear largely driving adaptive behaviors that enable avoidance of actual or impending harm. This therefore subserves the key function of pain, to protect the integrity and survival of an organism. Moreover, the role of emotions and state of mind in pain partly underlie

Address correspondence and reprint requests to: Kirsty Bannister, Ph.D., Department of Neuroscience, Physiology and Pharmacology, Division of Bioscience, University College London, Gower Street, London WC1E 6BT, UK. E-mail: kirsty.bannister@ucl.ac.uk. the variable relationship between the intensity of damaging stimuli and perceived pain, such that at any given time and for any given nociceptive stimulus, painful response can be influenced by emotional state (the psychological context in which the stimulus is received), emotional trait (the psychological characteristics of the recipient), and cognitive set (attention and vigilance, for example).

Depression is associated with abnormalities in the monoaminergic system, and in particular serotonin (5HT) and noradrenaline (NA), neurotransmitters that are also implicated in the control of the nociceptive system and particularly chronic pain. Chronic pain is a blanket term for persistent pain that outlasts its biological usefulness, existing beyond the time it takes for injuries to heal, or possibly occurring in the absence of any precipitating cause. Midbrain and brainstem areas including the periaqueductal gray (PAG) form the depression-pain interface and are therefore targets for antidepressant action, with respect to both complaints. The PAG is the structural relay that mediates information sent from the limbic forebrain and midbrain structures (including the amyg- 
dala, hypothalamus, and neocortex) to the brainstem, and in particular the rostral ventromedial medulla (RVM), which has the 5-HT-rich nucleus raphe magnus at its core and sits at the base of the brain close to the pontomedullary junction. This position ideally allows the RVM to filter neuronal signals that pass down to the dorsal horn to alter the volume of spinal sensory processing, which means that sensory information from the periphery that synapses in the dorsal horn of the spinal cord is subjected to supraspinal modulation as a matter of course.

Studies that link the anatomy and pharmacology of dorsal horn neurons and descending facilitatory pathways have provided a better understanding of the neuronal plasticity associated with a peripheral insult. Descending pathways from the brain regulate changes in spinal sensitivity via an interaction between spinal and supraspinal circuits in, for example, neuropathy and, possibly, in opioid-induced hyperalgesia $(\mathrm{OIH})$. Selectively ablating superficial neurokinin-1 (NK1) receptor-expressing neurons in the dorsal horn of the spinal cord reduce pain sensitivity after nerve injury, reducing the neuronal receptive field and causing a loss of graded response to noxious thermal and mechanical heat coding. 4

Superficial lamina 1 neurons form a major part of ascending pathways to the brainstem that indirectly drive descending serotonergic inputs to the spinal cord. ${ }^{5-7}$ Having confirmed that ablation of lamina 1 NK1 receptor-expressing neurons affected deep dorsal horn widedynamic-range neuronal responses to mechanical and thermal stimuli, Suzuki et al. ${ }^{8}$ investigated whether alterations in descending controls could account for the neuronal coding changes observed. Indeed, by blocking the action of 5-HT at the 5- $\mathrm{HT}_{3}$ receptor with ondansetron, the majority of wide-dynamic-range neuronal responses recorded after NK1 receptor-expressing neuronal destruction were reproduced, indicating the likelihood of a decreased descending excitatory influence of the widedynamic-range neurons, ${ }^{8}$ providing a circuit for a spinobulbo-spinal facilitatory loop with the descending arm terminating on spinal $5-\mathrm{HT}_{3}$ receptors.

\section{DESCENDING MODULATORY PATHWAYS}

The modulated spinal signal is transferred up to supraspinal areas via functionally separate yet anatomically parallel pathways, which, together with their targets, decode the nociceptive signal into an elaborate pain experience. These pathways, including the spinoparabrachial and spinothalamic pathways, relay through areas that attach emotional and contextual meaning to the nociceptive signal (the medial prefrontal cortex, insular cortex, anterior temporal cortex, hypothalamus, and amygdala all send neuronal projections to sensory sorting areas within the midbrain and brainstem), in addition to areas that align homeostatic processes such as blood pressure and heart rate to the requirements of the signal. Thus, limbic, cognitive, somatic, and homeostatic areas of the brain are informed of the incoming nociceptive signal and ultimately converge into a descending modulatory system that feeds down to the dorsal horn to affect further incoming inputs into the spinal cord, causing the feedback cycle to continue. This spino-bulbo-spinal loop therefore provides the basic neural framework that enables the brain to have final control over nociceptive processing in the spinal cord.

Efferent limbs of the descending modulatory system that form final filters for supraspinal signals that pass to the spinal cord include the RVM and the dorsal lateral pontine tegmentum, a brainstem area that clusters together cell bodies of noradrenergic neurons. Descending projections of the RVM travel in the dorsolateral funiculus and branch bilaterally in the dorsal horn, ${ }^{9,10}$ whereupon synapses are made with the terminals of primary afferent neurons, ascending tract neurons, intrinsic interneurons, and the terminals of other descending neurons in laminae I, II, and V, which are dorsal horn territories populated by the central terminals of nociceptive neurons. ${ }^{11}$ The RVM does not, however, exclusively serve nociception; its neurons also descend to lamina $\mathrm{X}$ to modulate parasympathetic and sympathetic outflow, affecting autonomic targets such as the heart, blood vessels, and adrenal medulla in circumstances that may or may not relate to the presence of pain.

Following the lead of the PAG, the RVM gives rise to descending pathways that differentially engage facilitatory and inhibitory neurons to respectively increase and decrease dorsal horn activity. The relative recruitment of these neurons can alter under different conditions and circumstances such that spinal sensory transmission may be potentiated or suppressed. The neural basis for this bidirectional modulation has long been established ${ }^{12}$ : the On cells burst-fire in response to peripheral noxious stimuli, enhance nociception and are implicated in the hypersensitivities associated with a range of pain states, ${ }^{13-15}$ whereas Off cells undergo a pause in firing in response to peripheral noxious stimuli and are involved in inhibiting spinal neuronal activity. ${ }^{16,17}$ The responses of these RVM neurons to noxious stimuli are inversely predictive of their responses to systemic or local opioid administration ${ }^{12,18}$; hence, On cells are inhibited by morphine, but Off cells are (indirectly) activated.

In vitro RVM recordings have shown that a large proportion of spinally projecting neurons respond directly to $\mu$-opioid receptor (MOR) agonists, ${ }^{19}$ which confirms the central role of the brainstem in opioid analgesia. $^{20,21}$ Moreover, many MOR-expressing spinally projecting neurons in the RVM stain positive for tryptophan hydroxylase, a marker of 5-HT content, and like- 
wise, many tryptophan hydroxylase-positive spinally projecting neurons respond to MOR agonists.

Because RVM On and Off cells are primarily classified according to predictive changes in their activity after peripheral noxious stimulation, ${ }^{22}$ they cannot be identified in slice preparations. Nonetheless, comparisons of behavioral and in vitro studies suggest that cells labeled primary cells in vitro are similar to Off cells in vivo, whereas secondary cells in vitro are similar to On cells in vivo. Under this analogy, putative On cells are directly hyperpolarized and inhibited by MOR agonists such as morphine, whereas putative Off cells receive $\mu$-opioidsensitive GABAergic inputs (i.e., morphine disinhibits Off cell firing), ${ }^{23}$ which neatly explains the neuronal mechanisms of central morphine-induced antinociception. ${ }^{24}$ Furthermore, the fact that many 5-HT-containing neurons respond directly to MOR agonists (i.e., they are facilitatory On cells) lends support to the idea that serotonergic mechanisms are intrinsically part of the facilitatory output of the brainstem.

\section{5-HT FUNCTION IN DIFFERENT PAIN STATES}

Tissue injury in the periphery induces the release of 5-HT from platelets, ${ }^{25}$ which activates nociceptors by direct means, in addition to sensitizing nociceptive neurons to the algesic actions of other agents, such as bradykinin. This can be demonstrated in the skin with 2-methyl 5-HT, an agent that has relatively selective affinity for excitatory 5 - $\mathrm{HT}_{3}$ receptors, and can be blocked by the competitive $5-\mathrm{HT}_{3}$ receptor antagonist tropisetron. ${ }^{26}$ This relatively straightforward sequence of events and outcomes does not, however, translate to the CNS, where the nociceptive modulatory actions of 5-HT are several degrees more complex.

The variable capacity of 5-HT to differentially inhibit $^{27-29}$ or facilitate ${ }^{28,30-32}$ nociception within the CNS is a function of the multiple 5-HT receptor subtypes that are expressed throughout the sensory neuraxis, which may mediate reciprocal and even antagonistic actions, depending on the membrane and intracellular processes that they are coupled to. The above-mentioned $5-\mathrm{HT}_{3}$ receptors, for example, gate cation channels to conduct rapid synaptic depolarization upon 5-HT (or agonist) binding. ${ }^{33}$

5-HT therefore promotes nociception in the spinal cord by enhancing the release of substance $\mathrm{P}$, calcitonin gene-related peptide, and neurokinin A from the central terminals of primary afferent fibers that express $5-\mathrm{HT}_{3}$ receptors. ${ }^{34,35}$ This explains the comparable ability of intrathecal substance P and 5-HT to induce behavioral hypersensitivities, an effect that is reversed in both circumstances by a NK1 receptor antagonist. ${ }^{36,37}$ Given their expression on the terminals of these nociceptive fibers, 5- $\mathrm{HT}_{3}$ receptors are largely expressed in superficial laminae within dense plexuses that receive neuronal projections from the nucleus raphe magnus. ${ }^{38,39}$ There is, however, an anatomical route between the descending system and neurons in lamina $\mathrm{V}$ that is enabled by the presence of interspinal pathways. This therefore allows brainstem serotonergic neurons that terminate superficially within the spinal cord to innervate deeper laminae.

Some authors have proposed that RVM-mediated morphine analgesia requires the release of 5-HT from brainstem neurons onto inhibitory 5-HT receptors in the spinal cord. ${ }^{40,41}$ This hypothesis, however, contradicts cellular recordings from nucleus raphe magnus neurons, which show that activation of 5-HT-containing neurons is not necessary for morphine analgesia. ${ }^{42,43}$ Notwithstanding the increased concentration of 5-HT metabolites in spinal and supraspinal areas consequent to systemic morphine injection, ${ }^{44,45}$ and observations that 5-HT receptor antagonists can modulate morphine analgesia, ${ }^{41}$ it could be that morphine affects other processes that are under the direction of the RVM, such as behavioral state, which may themselves alter central serotonergic tone. Thus, any morphine-evoked increases in 5-HT release may be secondary to primary opioid effects. ${ }^{42}$

The $5-\mathrm{HT}_{1}$ receptors have been implicated in the inhibitory effects of 5-HT, and accordingly, 5- $\mathrm{HT}_{1 \mathrm{~B} / 1 \mathrm{D}}$ receptors are targets for agonist agents that treat migraine. ${ }^{46}$ With respect to noncranial pains, the antinociceptive actions of brainstem 5-HT are largely mediated by spinal $5-\mathrm{HT}_{1 \mathrm{~A}}$ receptors. Conversely, the pronociceptive actions of 5-HT are largely mediated by $5-\mathrm{HT}_{2 \mathrm{~A}}$ and $5-\mathrm{HT}_{3}$ receptors. ${ }^{32,47-51}$ Nonetheless, there are also reports of paradoxical hypoalgesia to acute pain responses after the spinal stimulation of these excitatory receptors. ${ }^{52-54}$ Given that antagonists to either $5-\mathrm{HT}_{3}$ or GABA receptors could block these inhibitory responses, the underlying antinociceptive mechanisms likely involve the 5-HT-mediated release of GABA from inhibitory interneurons in this case.

The number of $5-\mathrm{HT}_{3}$ receptors in the dorsal horn can be greatly reduced by neonatal capsaicin treatment or dorsal rhizotomy, ${ }^{55,56}$ which suggests that these receptors are expressed predominantly on peripheral nerve fibers and terminals, but that those remaining may represent $5-\mathrm{HT}_{3}$ receptors on inhibitory interneurons in the spinal cord. ${ }^{57}$ Given the predominantly pronociceptive effect of 5-HT acting at $5-\mathrm{HT}_{3}$ receptors, however, and the clinical analgesic potential of the selective 5- $\mathrm{HT}_{3}$ receptor antagonist ondansetron, ${ }^{58}$ these presumptive GABA-dependent inhibitory effects may be masked by upregulated descending serotonergic facilitatory effects in the pathophysiological setting. ${ }^{51}$ Thus, for example, intrathecal 5-HT has a dose-dependent dual effect on nociceptive processing, with low concentrations reducing formalininduced nocifensive responses and higher doses increas- 
ing them, ${ }^{59}$ which fits with observations that intrathecal $5-\mathrm{HT}_{3}$ receptor antagonists reduce only the second phase of the formalin response (i.e., the phase that involves centrally mediated mechanisms).

It is possible that spinal serotonergic facilitations occur in persistent rather than acute pain states, ${ }^{51}$ which implies that this system has a key role in supporting ongoing pain. Animal studies have shown that, soon after spinal cord injury, there is a three-fold increase in 5-HTcontaining fibers in superficial laminae immediately rostral to the lesion site within spinal segments contributing to allodynic dermatomes. ${ }^{60}$ Exogenous delivery of 5-HT to the spinal cord transiently reduced mechanical hypersensitivities, but long-term hypersensitivities were maintained via $5-\mathrm{HT}_{3}$ receptor activity: ondansetron dose-dependently reduced at-level mechanical allodynia, whereas application of a specific $5-\mathrm{HT}_{3}$ receptor agonist potentiated behavioral measures of nociception. Moreover, ablation of serotonergic neurons with 5,7-DHT ([5, 7, dihydroxytryptamine] a neurotoxin that depletes cells of 5-HT without influencing other neural and nonneuronal systems ${ }^{61}$ ) significantly reduced behavioral hypersensitivities and prevented the inhibitory actions of spinal ondansetron. This suggests that the increased density of 5-HT-containing neurons in the spinal cord may have initially reduced nociception, possibly via actions on $5-\mathrm{HT}_{1}$ or $5-\mathrm{HT}_{2}$ receptors, whereas the more enduring effect of this enhanced brainstem input (the brainstem being the exclusive source of spinal 5-HT) was spinal facilitation. This introduces the concept of distinct, albeit overlapping, mechanisms that may initiate and maintain chronic pain.

Indeed, the pain modulatory effects of supraspinal 5-HT depend not only on the type of receptor stimulated, but also on the duration of pain and its pathophysiology. With respect to neuropathic injuries, local anesthetic block of the RVM, lesions of the dorsolateral funiculus pathway or selective ablation of MOR-expressing RVM neurons can each reduce behavioral indices of pain to baseline levels in spinal-nerve-ligated animals, but at late postoperative time points only. ${ }^{13,62,63}$ It has therefore been suggested that in neuropathic pain, supraspinal mechanisms have a larger role in maintenance stages as opposed to initiation and development. This latency may be a function of the brainstem needing sufficient priming by a barrage of hyperexcitable peripheral input to increase its facilitatory output. ${ }^{64}$ In this way, pain modulating neurons in the RVM exhibit a de novo response to innocuous mechanical stimulation after peripheral nerve injury, and become overly sensitive and enhance their output to noxious inputs. ${ }^{65}$ The involvement of the serotonergic system in mediating these late descending facilitatory effects is implied by parallel findings that neurotoxic depletion of endogenous spinal 5-HT causes a reduction in the evoked responses of deep dorsal horn neurons and attenuates behavioral hypersensitivities to mechanical and cold stimuli after nerve injury from postoperative day 7 onward (but not before). ${ }^{66}$

The $5-\mathrm{HT}_{3}$ receptor antagonist ondansetron has been shown to reduce responses to mechanical stimulation in spinal-nerve-ligated and naïve rats, ${ }^{51}$ which suggests that neuropathic pain states may be associated with enhanced descending facilitatory control of wide-dynamic-range spinal neurons through the activation of spinal $5-\mathrm{HT}_{3}$ receptors. The descending serotonergic pathway that terminates on $5-\mathrm{HT}_{3}$ receptors is also enhanced in animal models of cancer-induced bone pain, ${ }^{67}$ wherein the pain state is thought to include inflammatory and neuropathic components, as well as factors that are unique to the cancer-induced bone pain phenotype. ${ }^{68}$

The variable influence of the serotonergic system in inflammatory pain bears out the idea that there is differential brainstem activity in different pathophysiological settings. For example, 5- $\mathrm{HT}_{3}$ receptor-mediated descending facilitations prevail in the late phase of the formalin test $^{47}$ (similarly, in mice lacking the $5-\mathrm{HT}_{3 \mathrm{~A}}$ receptor there is reduced formalin sensitivity ${ }^{49}$ ), but in the complete Freund's adjuvant model of inflammation, dominant descending facilitations eventually give way to dominant descending inhibitions. ${ }^{69}$

Preclinical promise has been translated to clinical application, and clinical investigations related to serotonergic pain modulation are ongoing. Aside from the aforementioned agonist agents that target $5-\mathrm{HT}_{1 \mathrm{~B} / 1 \mathrm{D}}$ receptors to relieve migraine, ${ }^{46}$ and antidepressant agents that are used in the mainline treatment of neuropathic pain (see below), 5-HT receptor modulators have been studied in clinical trials for the treatment of irritable bowel syndrome (IBS), a functional bowel disorder that is characterized by chronic abdominal pain, discomfort, and bloating. ${ }^{70}$ These agents, however, including alosetron and cilansetron, have fallen short of licensing approval because of dose-limiting adverse effects that include severe constipation and ischemic colitis. In particular, as well as reducing visceral pain in patients with IBS, ${ }^{71}$ alosetron also decreases activity in various limbic structures in response to colorectal distension, which may in part explain its analgesic efficacy.

This is noteworthy, because abnormal activity in higher brain, midbrain, and brainstem circuits that sort and merge the sensory, contextual, and emotional components of pain may potentially explain some diffuse pain states, including IBS and fibromyalgia syndrome (FMS), a disorder associated with tenderness and pain in all quadrants of the body. ${ }^{72,73}$ The signs and symptoms of FMS do not relate to any apparent peripheral neuronal pathology, and histological examinations of muscle biopsies from affected patients show no obvious tissue abnormalities $^{74}$; hence, the pathogenesis is thought to be centrally based. Several features of presentation and 
treatment of FMS support this hypothesis. For example, wide-spread allodynia is symmetrically distributed to the rostrocaudal axis, and patients have a greater level of temporal summation after repetitive thermal stimulation, which suggests that central sensitization has occurred. ${ }^{75}$ Furthermore, central disruptions are indicated by elevated levels of substance $P$ in the cerebrospinal fluid and by altered 5 -HT metabolism, ${ }^{76}$ the same neurotransmitters that are respectively implicated in the origin and conclusion of the spino-bulbo-spinal facilitatory loop. ${ }^{8}$

Such findings may explain the rationale for using antidepressants, and the tricyclic agent (TCA) amitriptyline in particular, to relieve painful symptoms in affected patients. ${ }^{77}$ Moreover, antidepressant efficacy in the treatment of FMS may reflect the current understanding of the syndrome as a dynamic and individualized interplay of biological and psychological factors.

Just as some pathophysiological states depend on activity in the supraspinal modulatory system, so too does the efficacy of certain agents used to treat these pathophysiologies. Gabapentin and pregabalin, for example, are drugs that are used in the treatment of neuropathic pain and FMS. As ligands for the $\alpha_{2} \delta$ subunits of voltagegated calcium channels, these agents reduce trafficking of the channels from intracellular sources to neuronal membranes, thereby reducing synaptic transmission within the dorsal horn of the spinal cord. ${ }^{78}$ Nonetheless, the efficacy of these agents in acute preparations and shortterm inflammatory pain models in which $\alpha_{2} \delta$ upregulation does not occur ${ }^{79-83}$ suggests an alternative or parallel method of action. The descending monoaminergic system in particular has been implicated in this, with different researchers demonstrating the involvement of the descending noradrenergic system and the dependence on the descending serotonergic system in the analgesic actions of gabapentinoid drugs. ${ }^{62,83-85}$ The contribution of descending systems (which are influenced by cortical structures) could in part explain the variable and sometimes refractory response to analgesic agents in homogenous pain groups. ${ }^{86}$ Indeed, consistent efficacy of these agents in animal models of neuropathic pain does not translate to the clinic, where there is a tenuous link between the presence of nervous system lesions or abnormal sensory phenomena and responsiveness to these agents. ${ }^{87}$

\section{NORADRENALINE FUNCTION IN DIFFERENT PAIN STATES}

Noradrenaline is another key monoamine involved in endogenous pain modulation. In the periphery, NA is supplied by the circulation and released from postganglionic sympathetic neurons, whereas centrally it is sourced from brainstem nuclei (A1-A7) that project neurons to spinal loci in a similar manner as the descending serotonergic system. ${ }^{39,88}$ These noradrenergic neurons typically inhibit spinal cord activity via actions at $\alpha_{2}$ adrenoceptors (ARs), and in particular $\alpha_{2 \mathrm{~A}}$-ARs that are expressed on the central terminals of substance P-containing C-fibers (which suggests a presynaptic mode of action), and also $\alpha_{2 \mathrm{C}}$-ARs that are expressed on the axons of spinal projection neurons (these receptors therefore mediate postsynaptic inhibition). Furthermore, NA may cause spinal inhibition by activating excitatory $\alpha_{1-}$ ARs on inhibitory interneurons within the spinal cord. Like 5-HT, NA can variably influence nociceptive processing, depending on the mix and subtype of adrenoceptors activated, as well as on the presence, duration, and nature of pain. Regarding the former, application of NA to the skin of healthy human subjects does not elicit pain, but it may evoke hyperalgesia in response to thermal stimuli, ${ }^{89}$ and can potentiate pain in inflamed or neuropathic skin, possibly via $\alpha_{1}$-AR activation. ${ }^{90,91}$ Similarly, intact primary afferent fibers are only marginally (if at all) affected by noradrenaline, ${ }^{92}$ but become receptive after injury. ${ }^{93}$

In spinal-nerve-ligated rats, the selective $\alpha_{2}$-AR antagonist atipamezole failed to have an effect on spinal cord neuronal responses to peripheral stimuli, which suggests a downregulation of this endogenous inhibitory system in this pain model. ${ }^{94}$ Given the increased behavioral responses of rats to mechanical stimuli after nerve injury, it is not surprising, but still intriguing, that the shift to this abnormal state seemingly occurs in the direction of increased spinal $5-\mathrm{HT}_{3}$ receptor-mediated facilitations that are matched by reduced $\alpha_{2}$-AR-mediated inhibitory controls.

Both TCA and serotonin and noradrenaline reuptake inhibitor (SNRI) antidepressant agents relieve pain partly by enhancing longevity of NA in the synapse to restore these inhibitory controls. On balance, noradrenergic mechanisms may dominate over serotonergic mechanisms with respect to the pain-relieving capacity of certain antidepressant agents, and this is reflected in the antidepressant efficacy league table: meta-analyses indicate that TCAs that variably affect both NA and 5-HT synaptic transmission have a number needed to treat (NNT) of 2-3, whereas dual transport inhibitors (the SNRIs) lag behind with a NNT of $4-5$. NNT is a statistical term that allows the effectiveness of different analgesic agents to be compared. It refers to the number of patients who need to be treated to prevent one adverse outcome. The lower the number, the more effective the analgesic. Lagging still further are the selective serotonin reuptake inhibitors (SSRIs), with a NNT of 7. Indeed, in mutant mice lacking central serotonergic neurons, fluoxetine, a SSRI, failed to affect behavioral scores of inflammatory pain, whereas duloxetine, a SNRI remained effective, albeit at a lower analgesic efficacy. ${ }^{95}$ This latter class of drug is being forwarded as an alternative to TCAs in the main- 
line treatment of various chronic pain conditions owing to superior tolerability and lower adverse effects. Another agent, tapentadol, achieves broad-spectrum analgesic action by combining agonist activity at MORs with inhibition of NA reuptake, thus facilitating monoaminergic transmission in descending pain inhibitory pathways. ${ }^{50}$ Doubts remain about the true analgesic efficacy of SSRIs, ${ }^{96}$ which selectively modulate serotonergic content at the synapse, with the reported moderate or clinically insufficient analgesia possibly attributable to anxiolytic effects. ${ }^{97,98}$

\section{DOPAMINE}

Dopamine (DA) is the third monoamine whose central circuitry has a suspected role in pain processing. ${ }^{99,100} \mathrm{In}$ particular, it is thought that DA produces analgesic effects via interactions with endogenous opioids in midbrain areas. ${ }^{101}$ The PAG, for example (a key site for opioid action), contains a subpopulation of dopaminergic neurons that, if ablated or antagonized, attenuate the antinociceptive effects of systemic morphine. ${ }^{102}$ On the other hand, DA receptor agonists and DA transport inhibitors enhance the antinociceptive effects of opioids. ${ }^{103}$ Clinical support for a link between DA and pain processing comes from imaging studies in humans, ${ }^{104}$ in addition to empirical and anecdotal reports of increased frequency and diversity of hitherto unexplainable pain symptoms in patients with Parkinson's disease, some of which are pathology specific (e.g., dystonic spasms) and some of which are not (e.g., musculoskeletal and low back pain). ${ }^{105}$ Further research is needed to map the link between dopamine and the reward pathways in the brain to the ascending and descending pathways and pain.

\section{OPIOID-INDUCED HYPERALGESIA}

Opioid analgesics remain the treatment of choice for the long-term management of moderate to severe cancer pain, and are increasingly used to treat chronic to acute noncancer pain. As the worldwide older population expands, the number of people with terminal cancer increases and palliative and hospice care grows. Thus, so too does the worldwide licit consumption of opioids.

The development of analgesic tolerance with prolonged opioid use has proved an unfortunate obstacle in the clinic, where patients rely on the unrivaled potency of opioid-induced pain relief. In addition, chronic opioid consumption can lower pain thresholds, resulting in heightened atypical pain sensations that are unrelated to the original nociceptive stimulus, manifesting in a distinct location with an altered distribution to that reported originally. This paradox, referred to as opioid-induced hyperalgesia $(\mathrm{OIH})$, is accepted as a clinical reality in humans ${ }^{106}$; it is defined as the need for increasingly higher levels of opioids to maintain pain inhibition after repeated drug exposure.

The manifestation of OIH and opioid tolerance may be a result of the activation of pronociceptive pathways that counteract analgesic effects. Neural plasticity, possibly initiated via opioid receptor interactions, ${ }^{107}$ is associated with both tolerance and $\mathrm{OIH}$ at the preclinical level, where characteristics most commonly associated with neuropathy (tactile allodynia, thermal hyperalgesia, opioid tolerance, and increased spinal dynorphin content) are evident after spinal infusion of MOR agonist. ${ }^{108}$ This is the case even though there is no peripheral insult in OIH (although there is an abnormal pain state), unlike the situation in neuropathic pain, cancer pain, and inflammation. Opioid-induced hyperalgesia thus provides an intriguing model for unraveling central mechanisms of hypersensitivity that occurs despite normal peripheral activity.

The precise molecular mechanisms underlying $\mathrm{OIH}$, which can be readily induced and measured in animals, are not fully understood and remain under investigation. Osmotic minipumps, which allow the continuous infusion of loaded substance into experimental animals, have provided an invaluable tool for monitoring the effects of chronic drug treatment in the absence of withdrawal. ${ }^{109}$ It is widely accepted that the pathophysiology of $\mathrm{OIH}$ can be attributed to neuroadaptive alterations in the central and peripheral nervous system, leading to sensitization of pronociceptive pathways. Mechanisms of action proposed to be essential for the development of an increased sensitivity to pain resulting from long-term exposure to opiates include enhanced NK1 receptor transmission. ${ }^{110}$ Experiments performed previously have shown that sustained morphine exposure increases pronociceptive agent substance $\mathrm{P}$ and NK1 receptor expression in the spinal dorsal horn. ${ }^{110}$

Moreover, spinal administration of the NK1 receptor antagonist L-732,138 fully reversed thermal hypersensitivity in rats receiving sustained morphine treatment via a subcutaneous morphine-pellet implant. ${ }^{111}$ Interestingly, morphine-induced hyperalgesia was not observed in NK1 receptor knockout $\left(\mathrm{NK}^{---}\right)$mice, providing evidence for a critical involvement of the NK1 receptor in the manifestation of morphine-induced hyperalgesia. These spinal NK1 expressing neurons are at the origin of the input pathways into midbrain and brainstem modulatory systems. ${ }^{8}$

There is a large body of evidence to suggest that higher CNS centers may support OIH through enhanced descending facilitation to the spinal cord dorsal horn. Spinal cord dorsal horn neuronal hyperexcitability and increased receptive field was recorded in rats after chronic morphine delivery. ${ }^{112}$ The paradoxical pain associated with $\mathrm{OIH}$, and the development of tolerance to the antinociceptive effects of opioids, are likely second- 
ary to neuroplastic changes that result, in part, from activation of compensatory facilitatory descending pain pathways arising from the RVM. Cholecystokinin is proposed to support the expression of sustained OIH after its release in the RVM. Cholecystokinin, acting through $\mathrm{CCK}_{2}$ receptors, activates the RVM and supports descending facilitations. ${ }^{113}$ This pronociceptive mechanism leads to secondary consequences, such as the upregulation of spinal dynorphin, a physiological antagonist to morphine. Chronic opioid treatment coincides with an elevation in the content of spinal dynorphin, ${ }^{114}$ a pain-enhancing agent that relies on intact descending facilitatory pathways from the RVM, which may promote the release of excitatory neurotransmitters from primary afferent fibers. This provides a positive feedback loop, enhancing the pain state and amplifying future sensory input.

In support of interactions linking persistent opioid exposure, increased spinal dynorphin expression, tonic activation of descending facilitation, and abnormal opioidinduced pain, studies have shown that, variously, a) microinjection of local anesthetic to stop neuronal discharge from the RVM, b) lesioning the dorsolateral funiculus prevents, or c) blocking spinal $5-\mathrm{HT}_{3}$ receptors reverses OIH and opioid tolerance. ${ }^{109,115}$

In $\mathrm{OIH}$, excitatory events in the CNS occur in the absence of peripheral hyperexcitability. ${ }^{108}$ Thus, it is possible that a compensatory serotonergic facilitatory system, including the stimulation of On cells in the RVM (which release 5-HT in the spinal cord leading to facilitation), is upregulated in the brainstem during OIH in a similar fashion to that which occurs after nerve injury. In favor of such a model, it has been shown that ondansetron blocks OIH, as well as opioid tolerance, after spinal administration in chronic-morphine treated rats with no peripheral injury. ${ }^{116}$

Concerns remain regarding physical dependence, addiction, adverse effects such as hyperalgesia, and dose escalation to overcome tolerance during opioid therapy. Even so, morphine will remain the gold standard opioid against which others are judged until a drug is found that produces fewer adverse effects at a dose that provides the same analgesia. In the mean time, it remains vital to conduct experiments aimed at understanding the neurochemical and neuroplastic changes that occur during sustained opioid treatment. Ultimately, combination therapies involving drugs that block OIH may offer a solution to the problems associated with chronic opioid treatment.

\section{SUMMARY}

Overall, the pharmacological substrates for descending modulation allow for a rational explanation for the use of various drugs in pain states in which descending modulations play key roles in the final pain experience. In this regard, drugs in clinical use, such as antidepres- sant agents, will obviously alter function within these descending monoamine pathways and have efficacy in both neuropathic and FMS pain states. Drugs that are most effective in neuropathy are the older TCAs and the newer SNRIs. The reduced actions of SSRI drugs supports the idea that NA inhibition is a key part of the analgesic effects.

This dual modulation of neuropathy (both peripheral and central), as well as of FMS, is also seen with gabapentin and pregabalin. Here it appears that the spinal regulation of calcium channel function through their $\alpha_{2} \delta$ subunit-binding site depends on descending facilitatory 5 - $\mathrm{HT}_{3}$-mediated influences from the RVM. Other studies have implicated increases in descending $\alpha_{2}$-AR-mediated inhibitions through supraspinal actions of gabapentin. ${ }^{85}$ Whereas the $5-\mathrm{HT}_{3}$ mechanism is clearly pain related and has been shown to be initiated by peripheral changes, this serotonergic system can also be activated in normal animals and in animals with $\mathrm{OIH}$, thus providing a rationale for an action of $\alpha_{2} \delta$ ligands in pains where the periphery does not have to be abnormal, which might be the case in FMS and IBS. Opioids have long been established as having both spinal actions and supraspinal effects; in the latter case, they activate Off cells and silence On cells, thus moving RVM output toward inhibition. ${ }^{22}$

Finally, other drugs may also interact with these systems. Tramadol, a weak opioid with both NA and 5-HT uptake block, has some efficacy in pain. In addition, the new agent tapentadol, a MOR agonist with NA reuptake inhibition, ${ }^{50}$ has a mechanism of action in which the factoring out of the 5-HT component would be expected to remove the potential pronociceptive effect of augmented 5-HT and also to reduce gastrointestinal and emetic actions. The $\mu$-opioid inhibition could then interact with the noradrenaline uptake inhibition to give an improved analgesic profile.

Hence, it is clear that, from original Cartesian views of pain as a fixed system that conducts peripheral pain signals to an alert and responsive brain, with continued research our understanding has evolved to a view of pain as a plastic, integrative, and highly individualized nociceptive system. ${ }^{117}$ This expands on early work by Sherrington ${ }^{118}$ that higher centers of the brain influence the transmission of nociceptive information, an idea empirically confirmed in 1954 by Hagbarth and Kerr, ${ }^{19}$ who proposed a descending system that could modulate pain. Thus, the focus of pain research was shifted away from its source and directed to the CNS. From seminal studies by Fields and Basbaum, ${ }^{120}$ and latterly by Fields and Heinricher, ${ }^{22}$ the circuitry of the complex descending nociceptive system is becoming understood. Several decades later, this research embraces the physiological and psychological factors that influence pain. Moreover, this relatively new way of thinking has had, and will continue 
to have, a profound influence on the management of pain, opening up a multifaceted approach to treatment and potential for new molecules.

Acknowledgments: Work relating to this review was funded by the Biotechnology and Biological Sciences Research Council (BBSRC), U.S. National Institutes of Health (NIH), and Wellcome Trust London Pain Consortium.

\section{REFERENCES}

1. Bair MJ, Robinson RL, Katon W, Kroenke K. Depression and pain comorbidity: a literature review. Arch Intern Med 2003;163: 2433-2445.

2. Meyer-Rosberg K, Kvarnström A, Kinnman E, Gordh T, Nordfors LO, Kristofferson A. Peripheral neuropathic pain: a multidimensional burden for patients. Eur J Pain 2001;5:379-389.

3. Katon W, Sullivan M, Walker E. Medical symptoms without identified pathology: relationship to psychiatric disorders, childhood and adult trauma, and personality traits. Ann Intern Med 2001;134:917-925.

4. Nichols ML, Allen BJ, Rogers SD, et al. Transmission of chronic nociception by spinal neurons expressing the substance $\mathrm{P}$ receptor. Science 1999;286:1558-1561.

5. Marshall GE, Shehab SA, Spike RC, Todd AJ. Neurokinin-1 receptors on lumbar spinothalamic neurons in the rat. Neuroscience 1996;72:255-263.

6. Todd AJ, McGill MM, Shehab SA. Neurokinin 1 receptor expression by neurons in laminae I, III and IV of the rat spinal dorsal horn that project to the brainstem. Neuroscience 2000;12: 689-700.

7. Polgár E, Puskár Z, Watt C, Matesz C, Todd AJ. Selective innervation of lamina I projection neurones that possess the neurokinin 1 receptor by serotonin-containing axons in the rat spinal cord. Neuroscience 2002;109:799-809.

8. Suzuki R, Morcuende S, Webber M, Hunt SP, Dickenson AH. Superficial NK1-expressing neurons control spinal excitability through activation of descending pathways. Nat Neurosci 2002; 5:1319-1326.

9. Holstege G, Kuypers HG. The anatomy of brain stem pathways to the spinal cord in cat: a labeled amino acid tracing study. Prog Brain Res 1982;57:145-175.

10. Jones SL, Light AR. Electrical stimulation in the medullary nucleus raphe magnus inhibits noxious heat-evoked fos protein-like immunoreactivity in the rat lumbar spinal cord. Brain Res 1990; 530:335-338.

11. Basbaum AI. Descending control of pain transmission: possible serotonergic-enkephalinergic interactions. Adv Exp Med Biol 1981;133:177-189.

12. Fields HL, Bry J, Hentall I, Zorman G. The activity of neurons in the rostral medulla of the rat during withdrawal from noxious heat. J Neurosci 1983;3:2545-2552.

13. Porreca F, Burgess SE, Gardell LR, et al. Inhibition of neuropathic pain by selective ablation of brainstem medullary cells expressing the $\mu$-opioid receptor. Neuroscience 2001;21:52815288.

14. Neubert MJ, Kincaid W, Heinricher MM. Nociceptive facilitating neurons in the rostral ventromedial medulla. Pain 2004;110:158165.

15. Vera-Portocarrero LP, Xie JY, Kowal J, Ossipov MH, King T, Porreca F. Descending facilitation from the rostral ventromedial medulla maintains visceral pain in rats with experimental pancreatitis. Gastroenterology 2006;130:2155-2164.

16. Heinricher MM, Morgan MM, Tortorici V, Fields HL. Disinhibition of off-cells and antinociception produced by an opioid action within the rostral ventromedial medulla. Neuroscience 1994;63:279-288.

17. Heinricher MM, Schouten JC, Jobst EE. Activation of brainstem $\mathrm{N}$-methyl-D-aspartate receptors is required for the analgesic actions of morphine given systemically. Pain 2001;92:129-138.
18. Barbaro NM, Heinricher MM, Fields HL. Putative pain modulating neurons in the rostral ventral medulla: reflex-related activity predicts effects of morphine. Brain Res 1986;366:203-210.

19. Marinelli S, Vaughan CW, Schnell SA, Wessendorf MW, Christie MJ. Rostral ventromedial medulla neurons that project to the spinal cord express multiple opioid receptor phenotypes. J Neuroscience 2002;22:10847-10855.

20. Fields HL, Heinricher MM, Mason P. Neurotransmitters in nociceptive modulatory circuits. Annu Rev Neurosci 1991;14:219245.

21. Fields H. State-dependent opioid control of pain. Nat Rev Neurosci 2004;5:565-575.

22. Fields HL, Heinricher MM. Anatomy and physiology of a nociceptive modulatory system. Philos Trans R Soc Lond B Biol Sci 1985;308:361-374.

23. Pan ZZ, Tershner SA, Fields HL. Cellular mechanism for antianalgesic action of agonists of the kappa-opioid receptor. Nature 1997;389:382-385.

24. Ackley MA, Hurley RW, Virnich DE, Hammond DL. A cellular mechanism for the antinociceptive effect of a kappa opioid receptor agonist. Pain 2001;91:377-388.

25. Pierce PA, Xie GX, Peroutka SJ, Levine JD. Dual effect of the serotonin agonist, sumatriptan, on peripheral neurogenic inflammation. Reg Anesth 1996;21:219-225.

26. Richardson BP, Engel G, Donatsch P, Stadler PA. Identification of serotonin M-receptor subtypes and their specific blockade by a new class of drugs. Nature 1985;316:126-131.

27. Yaksh TL. Direct evidence that spinal serotonin and noradrenaline terminals mediate the spinal antinociceptive effects of morphine in the periaqueductal gray. Brain Res 1979;160:180-185.

28. Hylden JL, Wilcox GL. Intrathecal serotonin in mice: analgesia and inhibition of a spinal action of substance P. Life Sci 1983; 33:789-795.

29. Schmauss C, Hammond DL, Ochi JW, Yaksh TL. Pharmacological antagonism of the antinociceptive effects of serotonin in the rat spinal cord. Eur J Pharmacol 1983;90:349-357.

30. Jordan LM, Kenshalo DR Jr, Martin RF, Haber LH, Willis WD Two populations of spinothalamic tract neurons with opposite responses to 5-hydroxytryptamine. Brain Res 1979;164:342-346.

31. Vaught JL, Scott R. Interactions of substance P antagonists with serotonin in the mouse spinal cord. Peptides 1988;9:909-913.

32. Rahman W, Suzuki R, Rygh LJ, Dickenson AH. Descending serotonergic facilitation mediated through rat spinal $5 \mathrm{HT}_{3}$ receptors is unaltered following carrageenan inflammation. Neurosci Lett 2004;361:229-231.

33. Derkach V, Surprenant A, North RA. 5- $\mathrm{HT}_{3}$ receptors are membrane ion channels. Nature 1989;339:706-709.

34. Saria A, Javorsky F, Humpel C, Gamse R. 5- $\mathrm{HT}_{3}$ receptor antagonists inhibit sensory neuropeptide release from the rat spinal cord. Neuroreport 1990;1:104-106.

35. Inoue A, Hashimoto T, Hide I, Nishio H, Nakata Y. 5-Hydroxytryptamine-facilitated release of substance $\mathrm{P}$ from rat spinal cord slices is mediated by nitric oxide and cyclic GMP. J Neurochem 1997;68:128-133.

36. Fasmer OB, Berge OG, Walther B, Hole K. Changes in nociception after intrathecal administration of 5,6-dihydroxytryptamine in mice. Neuropharmacology 1983;22:1197-1201.

37. Fasmer OB, Post C. Behavioural responses induced by intrathecal injection of 5-hydroxytryptamine in mice are inhibited by a substance P antagonist, D-Pro2, D-Trp7,9-substance P. Neuropharmacology 1983;22:1397-1400.

38. Ruda MA, Bennett GJ, Dubner R. Neurochemistry and neural circuitry in the dorsal horn. Prog Brain Res 1986;66:219-268.

39. Kwiat GC, Basbaum AI. The origin of brainstem noradrenergic and serotonergic projections to the spinal cord dorsal horn in the rat. Somatosens Mot Res 1992;9:157-173.

40. Zhao ZQ, Gao YJ, Sun YG, Zhao CS, Gereau RW 4th, Chen ZF. Central serotonergic neurons are differentially required for opioid analgesia but not for morphine tolerance or morphine reward. Proc Natl Acad Sci U S A 2007;104:14519-14524.

41. Wigdor S, Wilcox GL. Central and systemic morphine-induced antinociception in mice: contribution of descending serotonergic 
and noradrenergic pathways. J Pharmacol Exp Ther 1987;242: 90-95.

42. Gao K, Chen DO, Genzen JR, Mason P. Activation of serotonergic neurons in the raphe magnus is not necessary for morphine analgesia. J Neurosci 1998;18:1860-1868.

43. Arvidsson U, Riedl M, Chakrabarti S, et al. Distribution and targeting of a $\mu$-opioid receptor (MOR1) in brain and spinal cord. J Neurosci 1995;15:3328-3341.

44. Matos FF, Rollema H, Brown JL, Basbaum AI. Do opioids evoke the release of serotonin in the spinal cord? An in vivo microdialysis study of the regulation of extracellular serotonin in the rat. Pain 1992;48:439-447.

45. Rivot JP, Pointis D, Besson JM. A comparison of the effects of morphine on 5-HT metabolism in the periaqueductal gray, ventromedial medulla and medullary dorsal horn: in vivo electrochemical studies in freely moving rats. Brain Res 1989;495:140 144.

46. Goadsby PJ. Serotonin receptors and the acute attack of migraine. Clin Neurosci 1998;5:18-23.

47. Green GM, Scarth J, Dickenson A. An excitatory role for 5-HT in spinal inflammatory nociceptive transmission; state-dependent actions via dorsal horn $5-\mathrm{HT}_{3}$ receptors in the anaesthetized rat. Pain 2000;89:81-88.

48. Sasaki M, Obata H, Kawahara K, Saito S, Goto F. Peripheral $5-\mathrm{HT}_{2 \mathrm{~A}}$ receptor antagonism attenuates primary thermal hyperalgesia and secondary mechanical allodynia after thermal injury in rats. Pain 2006;122:130-136.

49. Kayser V, Elfassi IE, Aubel B, et al. Mechanical, thermal and formalin-induced nociception is differentially altered in $5-\mathrm{HT}_{1 \mathrm{~A}}{ }^{-1-}$, $5-\mathrm{HT}_{1 \mathrm{~B}}{ }^{-1-}, 5-\mathrm{HT}_{2 \mathrm{~A}}{ }^{-1-}, 5-\mathrm{HT}_{3 \mathrm{~A}}{ }^{-1-}$ and $5-\mathrm{HTT}^{-1-}$ knock-out male mice. Pain 2007;130:235-248.

50. Tzschentke TM, Christoph T, Kögel B, et al. (-)-(1R,2R)-3-(3Dimethylamino-1-ethyl-2-methyl-propyl)-phenol hydrochloride (tapentadol $\mathrm{HCl}$ ): a novel $\mu$-opioid receptor agonist/norepinephrine reuptake inhibitor with broad-spectrum analgesic properties. J Pharmacol Exp Ther 2007;323:265-276.

51. Suzuki R, Rahman W, Hunt SP, Dickenson AH. Descending facilitatory control of mechanically evoked responses is enhanced in deep dorsal horn neurones following peripheral nerve injury. Brain Res 2004;1019:68-76.

52. Glaum SR, Anderson EG. Identification of $5-\mathrm{HT}_{3}$ binding sites in rat spinal cord synaptosomal membranes. Brain Res 1988;156: 287-290.

53. Glaum SR, Proudfit HK, Anderson EG. 5-HT 3 receptors modulate spinal nociceptive reflexes. Eur J Pharmacol 1990;510: $12-16$.

54. Crisp T, Stafinsky JL, Spanos LJ, et al. Analgesic effects of serotonin and receptor-selective serotonin agonists in the rat spinal cord. Gen Pharmacol 1991;22:247-251.

55. Hamon M, Gallissot MC, Menard F, Gozlan H, Bourgoin S, Vergé D. 5- $\mathrm{HT}_{3}$ receptor binding sites are on capsaicin-sensitive fibres in the rat spinal cord. Eur J Pharmacol 1989;164:315-322.

56. Kidd EJ, Laporte AM, Langlois X, et al. 5- $\mathrm{HT}_{3}$ receptors in the rat central nervous system are mainly located on nerve fibres and terminals. Brain Res 1993;612:289-298.

57. Kilpatrick GJ, Jones BJ, Tyers MB. Identification and distribution of $5-\mathrm{HT}_{3}$ receptors in rat brain using radioligand binding. Nature 1987;330:746-748.

58. McCleane GJ, Suzuki R, Dickenson AH. Does a single intravenous injection of the $5 \mathrm{HT}_{3}$ receptor antagonist ondansetron have an analgesic effect in neuropathic pain? A double-blinded, placebo-controlled cross-over study. Anesth Analg 2003;97:14741478.

59. Oyama T, Ueda M, Kuraishi Y, Akaike A, Satoh M. Dual effect of serotonin on formalin-induced nociception in the rat spinal cord. Neurosci Res 1996;25:129-135.

60. Oatway MA, Chen Y, Weaver LC. The 5-HT 3 receptor facilitates at-level mechanical allodynia following spinal cord injury. Pain 2004;110:259-268.

61. Duan J, Sawynok J. Enhancement of clonidine-induced analgesia by lesions induced with spinal and intracerebroventricular administration of 5,7-dihydroxytryptamine. Neuropharmacology 1987; 26:323-329.
62. Bee LA, Dickenson AH. Descending facilitation from the brainstem determines behavioural and neuronal hypersensitivity following nerve injury and efficacy of pregabalin. Pain 2008;140: 209-223.

63. Burgess SE, Gardell LR, Ossipov MH, et al. Time-dependent facilitation from the rostral ventromedial medulla maintains, but does not initiate, neuropathic pain. J Neurosci 2002;22:5129_ 5136.

64. Bee LA, Dickenson AH. Rostral ventromedial medulla control of spinal sensory processing in normal and pathophysiological states. Neuroscience 2007;147:786-793.

65. Carlson JD, Maire JJ, Martenson ME, Heinricher MM. Sensitization of pain-modulating neurons in the rostral ventromedial medulla after peripheral nerve injury. Neuroscience 2007;27: 13222-13231.

66. Rahman W, Suzuki R, Webber M, Hunt SP, Dickenson AH Depletion of endogenous spinal 5-HT attenuates the behavioural hypersensitivity to mechanical and cooling stimuli induced by spinal nerve ligation. Pain 2006;123:264-274.

67. Donovan-Rodriguez T, Urch CE, Dickenson AH. Evidence of a role for descending serotonergic facilitation in a rat model of cancer-induced bone pain. Neurosci Lett 2006;393:237-242.

68. Urch CE, Donovan-Rodriguez T, Dickenson AH. Alterations in dorsal horn neurones in a rat model of cancer-induced bone pain. Pain 2003;106:347-356.

69. Guan Y, Guo W, Robbins MT, Dubner R, Ren K. Changes in AMPA receptor phosphorylation in the rostral ventromedial medulla after inflammatory hyperalgesia in rats. Neurosci Lett 2004; 366:201-205.

70. Almy TP, Rothstein RI. Irritable bowel syndrome: classification and pathogenesis. Annu Rev Med 1987;38:257-265.

71. Wolfe SG, Chey WY, Washington MK, et al. Tolerability and safety of alosetron during long-term administration in female and male irritable bowel syndrome patients. Am J Gastroenterol 2001; 96:803-811.

72. Wolfe F, Amythe HA, Yunus MB, et al. The American College of Rheumatology 1990 Criteria for the Classification of Fibromyalgia. Report of the Multicenter Criteria Committee. Arthritis Rheum 1990;33:160-172.

73. Gracely RH, Grant MA, Giesecke T. Evoked pain measures in fibromyalgia. Exp Pract Res Clin Rheumatol 2003;17:593-609.

74. Schneider SP, Eckert WA 3rd, Light AR. Opioid-activated postsynaptic, inward rectifying potassium currents in whole cell recordings in substantia gelatinosa neurons. J Neurophysiol 1998; 80:2954-2962.

75. Staud R, Vierck CJ, Robinson ME, Price DD. Spatial summation of heat pain within and across dermatomes in fibromyalgia patients and pain-free subjects. Pain 2004;111:342-350.

76. Vaerøy H, Helle R, Førre O, Kåss E, Terenius L. Elevated CSF levels of substance $\mathrm{P}$ and high incidence of Raynaud phenomenon in patients with fibromyalgia: new features for diagnosis. Pain 1988;32:21-26.

77. Clauw DJ, Crofford LJ. Chronic widespread pain and fibromyalgia: what we know, and what we need to know. Best Pract Res Clin Rheumatol 2003;17:685-701.

78. Hendrich J, Van Minh AT, Heblich F, et al. Pharmacological disruption of calcium channel trafficking by the $\alpha_{2} \delta$ ligand gabapentin. Proc Natl Acad Sci U S A 2008;105:3628-3633.

79. Stanfa LC, Singh L, Williams RG, Dickenson AH. Gabapentin, ineffective in normal rats, markedly reduces C-fibre evoked responses after inflammation. Neuroreport 1997;8:587-590.

80. Iannetti GD, Zambreanu L, Wise RG, et al. Pharmacological modulation of pain-related brain activity during normal and central sensitization states in humans. Proc Natl Acad Sci U S A 2005;102:18195-18200.

81. Maneuf YP, Hughes J, McKnight AT. Gabapentin inhibits the substance P-facilitated $\mathrm{K}^{+}$-evoked release of $\left[{ }^{3} \mathrm{H}\right]$ glutamate from rat caudal trigeminal nucleus slices. Pain 2001;93:191-196.

82. Abe M, Kurihara T, Han W, Shinomiya K, Tanabe T. Changes in expression of voltage-dependent ion channel subunits in dorsal root ganglia of rats with radicular injury and pain. Spine (Phila Pa 1976) 2002;27:1517-1524; discussion 1525. 
83. Suzuki R, Rahman W, Rygh LJ, Webber M, Hunt SP, Dickenson AH. Spinal-supraspinal serotonergic circuits regulating neuropathic pain and its treatment with gabapentin. Neurosignals 2005;117: 292-303.

84. Takasu K, Honda M, Ono H, Tanabe M. Spinal $\alpha_{2}$-adrenergic and muscarinic receptors and the NO release cascade mediate supraspinally produced effectiveness of gabapentin at decreasing mechanical hypersensitivity in mice after partial nerve injury. Br J Pharmacol 2006;148:233-244.

85. Tanabe M, Takasu K, Kasuya N, Shimizu S, Honda M, Ono H. Role of descending noradrenergic system and spinal $\alpha_{2}$-adrenergic receptors in the effects of gabapentin on thermal and mechanical nociception after partial nerve injury in the mouse. $\mathrm{Br} \mathrm{J}$ Pharmacol 2005;144:703-714.

86. Sindrup SH, Jensen TS. Efficacy of pharmacological treatments of neuropathic pain: an update and effect related to mechanism of drug action. Pain 1999;83:389-400.

87. Rasmussen PV, Sindrup SH, Jensen TS, Bach FW. Therapeutic outcome in neuropathic pain: relationship to evidence of nervous system lesion. Eur J Neurol 2004;11:545-553.

88. Proudfit HK. Pharmacologic evidence for the modulation of nociception by noradrenergic neurons. Prog Brain Res 1988;77: 357-370.

89. Fuchs PN, Meyer RA, Raja SN. Heat, but not mechanical hyperalgesia, following adrenergic injections in normal human skin. Pain 2001;90:15-23.

90. Choi B, Rowbotham MC. Effect of adrenergic receptor activation on post-herpetic neuralgia pain and sensory disturbances. Pain 1997;69:55-63.

91. Ali Z, Raja SN, Wesselmann U, Fuchs PN, Meyer RA, Campbell JN. Intradermal injection of norepinephrine evokes pain in patients with sympathetically maintained pain. Pain 2000;88:161168.

92. Sato J, Perl ER. Adrenergic excitation of cutaneous pain receptors induced by peripheral nerve injury. Science 1991;251: $1608-1610$.

93. Bossut DF, Perl ER. Effects of nerve injury on sympathetic excitation of A delta mechanical nociceptors. J Neurophysiol 1995;73:1721-1723.

94. Rahman W, D’Mello R, Dickenson AH. Peripheral nerve injuryinduced changes in spinal $\alpha_{2}$-adrenoceptor-mediated modulation of mechanically evoked dorsal horn neuronal responses. J Pain 2008:9:350-359.

95. Zhao ZQ, Chiechio S, Sun YG, et al. Mice lacking central serotonergic neurons show enhanced inflammatory pain and an impaired analgesic response to antidepressant drugs. Proc Natl Acad Sci U S A 2007;27:6045-6053.

96. Max MB, Lynch SA, Muir J, Shoaf SE, Smoller B, Dubner R. Effects of desipramine, amitriptyline, and fluoxetine on pain in diabetic neuropathy. N Engl J Med 1992;326:1250-1256.

97. Saarto T, Wiffen PJ. Antidepressants for neuropathic pain [Update in: Cochrane Database Syst Rev 2007;(4):CD005454]. Cochrane Database Syst Rev 2005;(3):CD005454.

98. Sindrup SH, Otto M, Finnerup NB, Jensen TS. Antidepressants in the treatment of neuropathic pain. Basic Clin Pharmacol Toxicol 2005;96:399-409.

99. Greco R, Tassorelli C, Armentero MT, Sandrini G, Nappi G, Blandini F. Role of central dopaminergic circuitry in pain processing and nitroglycerin-induced hyperalgesia. Brain Res 2008; 1238:215-223.

100. Meyer PJ, Morgan MM, Kozell LB, Ingram SL. Contribution of dopamine receptors to periaqueductal gray-mediated antinociception. Psychopharmacology (Berl) 2009;204:531-540.
101. Zubieta JK, Heitzeg MM, Smith YR, et al. COMT val158met genotype affects $\mu$-opioid neurotransmitter responses to a pain stressor. Science 2003;299:1240-1243.

102. Flores JA, El Banoua F, Galán-Rodríguez B, Fernandez-Espejo E. Opiate anti-nociception is attenuated following lesion of large dopamine neurons of the periaqueductal grey: critical role for $D_{1}$ (not $\mathrm{D}_{2}$ ) dopamine receptors. Pain 2004;110:205-214.

103. Dalal S, Melzack R. Potentiation of opioid analgesia by psychostimulant drugs: a review. J Pain Symptom Manage 1998;16:245253.

104. Hagelberg N, Martikainen IK, Mansikka H, et al. Dopamine $D_{2}$ receptor binding in the human brain is associated with the response to painful stimulation and pain modulatory capacity. Pain 2002;99:273-279.

105. Giuffrida R, Vingerhoets FJ, Bogousslavsky J, Ghika J. Pain in Parkinson's disease [In French]. Rev Neurol (Paris) 2005;161: 407-418.

106. Arner S, Meyerson BA. Lack of analgesic effect of opioids on neuropathic and idiopathic forms of pain. Pain 1988;33:11-23.

107. Gardell LR, King T, Ossipov MH, et al. Opioid receptor-mediated hyperalgesia and antinociceptive tolerance induced by sustained opiate delivery. Neurosci Lett 2006;396:44-49.

108. Vanderah TW, Gardell LR, Burgess SE, et al. Dynorphin promotes abnormal pain and spinal opioid antinociceptive tolerance. J Neurosci 2000;20:7074-7079.

109. Vanderah TW, Ossipov MH, Lai J, Malan TP Jr, Porreca F. Mechanisms of opioid-induced pain and antinociceptive tolerance: descending facilitation and spinal dynorphin. Pain 2001;92: $5-9$.

110. King T, Ossipov MH, Vanderah TW, Porreca F, Lai J. Is paradoxical pain induced by sustained opioid exposure an underlying mechanism of opioid antinociceptive tolerance? Neurosignals 2005;14:194-205.

111. Cahill CM, Coderre TJ. Attenuation of hyperalgesia in a rat model of neuropathic pain after intrathecal pre- or post-treatment with a neurokinin-1 antagonist. Pain 2002;95:277-285.

112. Suzuki R, Porreca F, Dickenson AH. Evidence for spinal dorsal horn hyperexcitability in rats following sustained morphine exposure. Neurosci Lett 2006;407:156-161.

113. Xie JY, Herman DS, Stiller CO, et al. Cholecystokinin in the rostral ventromedial medulla mediates opioid-induced hyperalgesia and antinociceptive tolerance. J Neurosci 2005;25:409-416.

114. Vanderah TW, Suenaga NM, Ossipov MH, Malan TP Jr, Lai J, Porreca F. Tonic descending facilitation from the rostral ventromedial medulla mediates opioid-induced abnormal pain and antinociceptive tolerance. J Neurosci 2001;21:279-286.

115. Ossipov MH, Lai J, Malan TP Jr, Porreca F. Spinal and supraspinal mechanisms of neuropathic pain. Ann N Y Acad Sci 2000; 909:12-24.

116. Vera-Portocarrero LP, Zhang ET, King T, et al. Spinal NK-1 receptor expressing neurons mediate opioid-induced hyperalgesia and antinociceptive tolerance via activation of descending pathways. Pain 2007;129:35-45.

117. Melzack R, Wall PD. Pain mechanisms: a new theory. Science 1965;150:971-979.

118. Sherrington CS. Observations on the scratch-reflex in the spinal dog. J Physiol 1906;34:1-50.

119. Hagbarth KE, Kerr DI. Central influences on spinal afferent conduction. J Neurophysiol 1954;17:295-307.

120. Fields HL, Basbaum AI. Brainstem control of spinal pain-transmission neurons. Annu Rev Physiol 1978;40:217-248. 